\title{
Results of Frequency Analysis Distribution of Polymorphism Rs1800895 592C>A In IL10 Gene among Patients with Chronic Polypoid Rhinosinusitis
}

\author{
Jamolbek Abdukakhorovich Djuraev ${ }^{1 *}$, \\ Ulugbek Saydakramovich Khasanov', \\ Vokhidov Ulugbek Nuridinovuch ${ }^{3}$, \\ Shaumarov Azizkhon Zavkievich,
}

\begin{abstract}
Introduction: Chronic polyposis rhinosinusitis is a disease characterized by chronic inflammation of the nasal mucosa and sinuses. In the tissues of polyps and intranasal secretions, an increase in the concentration of various inflammatory mediators, in particular interleukins is observed due to an increase in their de novo synthesis by effector cells. The research objective to study the distribution of genotypic forms of the IL10 gene locus and evaluate their role in the development and clinical course of chronic polypoid rhinosinusitis.
\end{abstract}

Material and Methods: In accordance with the purpose of the study and to fulfill the assigned tasks, clinical studies were carried out in 140 patients with CPRS and with chronic rhinosinusitis, who were examined and treated at the ENT department of the multidisciplinary clinic of the Tashkent Medical Academy in 2017-2019. The examined patients met the following criteria: the presence of polyposis tissue in the nasal cavity that obstructs the common nasal passage completely or by at least $50 \%$; complaints of prolonged difficulty in nasal breathing; according to the patient, the disease significantly reduces the quality of his life; absence of acute inflammatory pathology; written informed consent for surgical treatment and morphological examination of the surgical material.

Results and Discussion:The revealed reliably high frequency of this genotype in group 1 of patients with CPRS, compared with group 2 of CPRS, also confirms our assumption about the protective role of the genotypic variant of the A/A polymorphism rs1800895 $592 \mathrm{C}>\mathrm{A}$ in the IL10 gene, in relation to the development of CPRS in patients $(6.45 \%$ versus $5.0 \%$, respectively, at $\chi 2=0.02 ; \mathrm{P}=0.45 ; \mathrm{RR}=1.17 ; \mathrm{OR}=1.18 ; 95 \% \mathrm{Cl}: 8.557-8.942)$. This fact is probably due to the fact that in carriers of the $\mathrm{A} / \mathrm{A}$ genotype of the IL10 gene, the anti-inflammatory activity of epithelial matrix metalloproteinases is significantly increased, compared with patients carrying other genotypic variants.

Conclusion: The results obtained showed that, with this pathology of the genotypic variant of the A/A polymorphism rs1800895 592 $\mathrm{C}>\mathrm{A}$ in the IL10 gene, there is a risk of developing CPRS in patients $(6.45 \%$ versus $5.0 \%$, respectively). This fact is probably due to the fact that in carriers of the A/A genotype of the IL10 gene, the anti-inflammatory activity of epithelial matrix metalloproteinases is significantly increased, compared with patients carrying other genotypic variants.

Keywords: Polyposis rhinosinusitis, Polymorphism, Genotype, Nasal mucosa, Cytokine.

1Doctor of Philosophy, Department of Otolaryngology and Stomatology, Tashkent Medical Academy, Tashkent, Republic of Uzbekistan ${ }^{2}$ Doctor of medical science Head of Department of Otolaryngology and Stomatology, Tashkent Medical Academy, Tashkent, Republic of Uzbekistan ${ }^{3}$ Doctor of Medical Science, Department of Otolaryngology, Tashkent State Dental Institute, Tashkent, Republic of Uzbekistan

${ }^{4}$ Doctor of Philosophy, Department of Otalaryngology and Somatology, Tashkent Medical Academy, Tashkent, Republic of Uzbekistan

*Doctor of medical science, professor, Head of the Department of Otolaryngology and Stomatology, Tashkent Medical Academy, Tashkent, Republic of Uzbekistan, E-mail: drdjuraev@mail.ru Phone: +998974000351

Paper submitted on July 30, 2021; and Accepted on November 26, 202 


\section{INTRODUCTION}

Chronic polyposis rhinosinusitis is a disease characterized by chronic inflammation of the nasal mucosa and sinuses. In the tissues of polyps and intranasal secretions, an increase in the concentration of various inflammatory mediators, in particular interleukins, is observed due to an increase in their de novo synthesis by effector cells ${ }^{1,2,3,4}$. Particular importance is attached to an increase in the concentration of cytokines involved in the development, recruitment and activation of eosinophils (IL-4, IL-12, IL-13, GM-CSF), the main pro-inflammatory (IL-1, IL2, TNF-a, IL-10), regulatory cytokines (IL-10, TLR2b), contributing to the chronicity of the inflammatory process in the nasal cavity ${ }^{5}$.

A hereditary predisposition to the development of CPRS suggests the role of genetic factors in its determination, but is not direct evidence of it. However, numerous studies indicate the association of interleukin gene polymorphism with the development, severity and chronicity of ENT diseases ${ }^{6,7}$.

The distribution of the allele frequencies of the resistance susceptibility genes that form the risk of development or resistance to multifactorial pathology is determined by the racial and ethnic origin of the studied group $8,9,10$

The cytokine system is a universal regulatory network of mediators designed to control proliferation, differentiation and functional activity of cellular elements in all homeostatic systems of the body, of which the immune system plays the most important role in the onset and development of diseases.

Cytokines - leukocyte inflammatory mediators are classified as pro- or anti-inflammatory regulatory peptides. The greatest role in pro-inflammatory processes is played by IL-1 and TNF-a. The mechanisms by which these cytokines are involved in the inflammatory response have much in common. They are able to enhance the expression of the COX-2 gene with a subsequent increase in the production of leukotrienes and prostaglandins and their involvement in the pathological process, thereby increasing the migration of leukocytes and inflammatory infiltration, and activating the endothelium. IL-6 and IL-8 also have pro-inflammatory properties. Antiinflammatory cytokines are active antagonists of IL-1 and TNF-a, the most active of which are IL-4 and IL10. Their anti-inflammatory activity is manifested in the suppression of the production of IL-1 and TNF-a, colony-stimulating factors, and a decrease in the cytotoxicity of macrophages.

Earlier, a number of studies have demonstrated a different ability to bind to transcription factors of alternative allelic variants in position -308 (G->A), which leads to an increase in the transcriptional activity of TNFA-308A compared to the TNFA-308G promoter. Substitution of guanine for adenine in this position increases gene expression and the level of TNF-a production in unstimulated cell lines of monocytes and T-lymphocytes ${ }^{11,12,13}$. Thus, the presence of the TNFA AA genotype may be one of the immunogenetic factors of predisposition to the development of a chronic pathological process with a pronounced and long-term inflammatory component.

We studied the promoter polymorphism of the IL10 gene, the protein product of which is the most important cytokine, which negatively regulates the inflammation process by suppressing the production of the main proinflammatory cytokines, such as IL-1, IL-2, IL-6, TNF-a and IFN-y ${ }^{14}$. The study of the ability of polyp tissue to produce this interleukin revealed an increase in the number of IL-10producing cells ${ }^{15}$; moreover, an increase in the content of IL-10 in the nasal secretion of CPRS patients was found ${ }^{16}$.

An increase in the serum level of IL- 6 and an increase in its production in cultures of epithelial cells of nasal polyps in patients with chronic rhinosinusitis ${ }^{17,18}$ indicates its direct role in maintaining the inflammatory process in NIN. On the other hand, IL-6 is an atypical pro-inflammatory cytokine and is capable of inhibiting the production of TNF-a, as well as inhibiting the proliferation of plasma cells - IgE producers during allergic inflammation ${ }^{19,20}$.

Numerous studies of the last decade have demonstrated the mechanism of formation of the polymorphic structure of the cytokine system-allelic polymorphism of cytokine genes $^{20}$. By studying the allelic polymorphism of cytokine genes, attempts are made to determine the genetic basis of individual characteristics of the immune response, in particular, the relationship between individual polymorphic alleles of cytokine genes and the production of a protein product. The result of such works in vitro is the identification of individual alleles of genes associated with increased or decreased production of the corresponding cytokine.

In modern medicine, high technologies are increasingly being used to diagnose diseases, and the attitude towards the earliest possible identification of minor changes in the body, leading subsequently to irreversible changes, is clearly expressed. It can be assumed that medical genetics can open up mechanisms for the earliest possible substitution therapy, will make it possible to treat the body with those products that it produces itself - i.e. restore self-regulation of the body as a system. Currently, the use of cytokine therapy based on the established genetic polymorphism belongs to experimental medicine, however, the first results obtained are stunning in their effectiveness and low cost compared to "traditional" methods of treatment

\section{MATERIALS AND METHODS}

In accordance with the purpose of the study and to fulfill the assigned tasks, clinical studies were carried out in 140 patients with CPRS and with chronic rhinosinusitis, who were examined and treated at the ENT department of the multidisciplinary clinic of the Tashkent Medical Academy in 2017-2019. The examined patients met the following criteria: the presence of polyposis tissue in the nasal cavity that obstructs the common nasal passage completely 
or by at least $50 \%$; complaints of prolonged difficulty in nasal breathing; according to the patient, the disease significantly reduces the quality of his life; absence of acute inflammatory pathology; written informed consent for surgical treatment and morphological examination of the surgical material (attached to the case history).

To study the diallelic polymorphism of the promoter regions of the genes of the studied interleukins, 50 healthy (without CPRS) donors, men and women, were examined. The average age of the examined donors was $51.3 \pm 1.44$ years.

For real-time PCR, a commercial kit with SYBRGreen I dye (Litekh, Russia) was used. The polymorphism of five positions of the IL10 rs1800895 592C>A gene was studied. Genotyping of the samples was carried out using allele-specific polymerase chain reaction (PCR) in real time on a DT-96 device (DNA-Technology) using the SYBR Green I intercalating dye. The reaction mixture corresponded to the manufacturer's recommendations.

The reaction began with the activation phase of Taq polymerase $\left(93^{\circ} \mathrm{C}, 1 \mathrm{~min}\right)$. The next 35 PCR cycles consisted of denaturation $\left(93^{\circ} \mathrm{C}, 10 \mathrm{sec}\right.$.), Annealing $\left(64^{\circ} \mathrm{C}, 15 \mathrm{sec}\right.$.) And elongation $\left(72^{\circ} \mathrm{C}, 20 \mathrm{sec}\right.$.) Phases. The signal was read at the stage of elongation.

\section{RESULTS AND DISCUSSION}

The study of the distribution of alleles and genotypes of rs1800895 polymorphism in the IL10 gene among patients with CPRS, CRS and among conditionally healthy individuals was carried out, the results of which are presented in Table 1

As can be seen from Table 1, in the main group, the prevalence of the $C$ allele was noted as compared to the $\mathrm{A}$ allele, the frequencies of which were $80.64 \%$ versus $19.35 \%$, respectively. In the control group, the frequency of allele $\mathrm{C}$, which was $82.9 \%$, also prevailed, compared with the frequency of allele $A$, which was $3.4 \%$. In general, the severity of differences was at a high level.

The distribution of genotypes $\mathrm{C} / \mathrm{C}, \mathrm{C} / \mathrm{A}$, and $\mathrm{A} / \mathrm{A}$ of the rs1800895 $592 \mathrm{C}>\mathrm{A}$ polymorphism in the IL10 gene was also investigated. In group 1 , the homozygous $\mathrm{C} / \mathrm{C}$ genotype was identified with the highest frequency, the detection rate of which was $67.74 \%$. Slightly lower values of this indicator were obtained in the study of the frequency of detection of the heterozygous C/A genotype, amounting to $25.8 \%$ (Table 1). At the same time, significantly lower values of the incidence, amounting to
$2.81 \%$, were revealed in the study of the A/A genotype among patients with CPRS, while in patients with CRS it was observed slightly higher than in patients with CPRS $(5 \%)$.

The study of the distribution of genotypes in the population group revealed differences between the values of the occurrence of genotypes characteristic, with insignificant differences, for group 1 . Also, as in group 1 , the highest detection rates among conventionally healthy individuals - $69.9 \%$ were found in the study of the homozygous $\mathrm{C} / \mathrm{C}$ genotype. The heterozygous $\mathrm{C} / \mathrm{A}$ genotype is also characterized by the presence of an insignificantly lower frequency of occurrence equal to $26.0 \%$. The least significant detection rate among conditionally healthy - $4.1 \%$, as well as among patients with CPRS, was established in the study of the homozygous genotype A/A (Table 2)

A comparative analysis of the occurrence of alleles and genotypes both in the control (group 3) and in the main (group 1) groups, the results of which are presented in Table 2.

Comparison of allele distribution frequencies in 1 and control groups showed that in the main group, the C-allele occurs statistically insignificantly more often than in the control group $(\chi 2=14.71 ; P=0.70 ; R R=0.83$; $\mathrm{OR}=0.14 ; 95 \% \mathrm{Cl}: 1.788-0.393)$. Comparison of allele distribution frequencies, in the main group, the A-allele occurs statistically significantly more often than in the control group $(\alpha 2=14.71 ; P=0.29 ; R R=1.19 ; O R=6.76$; 95\% Cl: 6.76-17.98). The A/A genotype was statistically insignificantly more often detected in the control sample, compared with the group of patients with CPRS. There were also no significant differences in the frequency of the heterozygous genotype, however, the analysis indicated an insignificantly higher frequency of its detection among patients with CPRS $(\chi 2=0.07 ; P=0.32$; $\mathrm{RR}=0.90 ; \mathrm{OR}=0.87 ; 95 \% \mathrm{Cl}$ : 3.305-2.267). A similar picture was observed in the study of the distribution of the homozygous genotype $A / A(\chi 2=0.16 ; P=0.31 ; R R=1.43$; $\mathrm{OR}=1.45 ; 95 \% \mathrm{Cl}: 12.63-9.06)$.

The results of the analysis of the occurrence of alleles and genotypes of the rs $1800895592 \mathrm{C}>\mathrm{A}$ polymorphism in the IL10 gene of group 2 patients with CRS and in the population sample (Table 3).

In the course of the study, it was found that as the occurrence of allele $\mathrm{C}$ was 1 group of patients with CPRS $81.25 \%$, this indicator was low compared with the control group, which was $96.58 \%(\chi 2=15.04 ; P=0.75 ; R R=0.84$;

Table 1: Frequency of distribution of alleles and genotypes of rs1800895 592 C> A polymorphism in the IL10 gene in patient and control groups.

\begin{tabular}{|c|c|c|c|c|c|c|c|c|c|c|c|}
\hline \multirow{3}{*}{ S.No } & \multirow{3}{*}{ Group } & \multicolumn{4}{|c|}{ Allele frequency } & \multicolumn{6}{|c|}{ Genotype distribution frequency } \\
\hline & & \multicolumn{2}{|c|}{ C } & \multicolumn{2}{|c|}{ A } & \multicolumn{2}{|c|}{$\mathbf{C} \backslash \mathbf{C}$} & \multicolumn{2}{|c|}{$\mathbf{C} \backslash \mathbf{A}$} & \multicolumn{2}{|c|}{$\mathbf{A} \backslash \mathbf{A}$} \\
\hline & & $\mathrm{n}$ & $\%$ & $\mathrm{n}$ & $\%$ & $\mathrm{n}$ & $\%$ & $\mathrm{n}$ & $\%$ & $\mathrm{n}$ & $\%$ \\
\hline 1 & CPRS $n=31$ & 50 & 80.64 & 12 & 19.35 & 21 & 67.74 & 8 & 25.80 & 2 & 2.81 \\
\hline 2 & CRS $n=40$ & 65 & 81.25 & 15 & 18.75 & 27 & 67.5 & 11 & 27.5 & 2 & 5 \\
\hline 3 & Control group $n=73$ & 121 & 82.9 & 5 & 3.4 & 51 & 69.9 & 19 & 26.0 & 3 & 4.1 \\
\hline
\end{tabular}


Table 2: Differences in the frequency of alleles and genotypes of the rs 1800895 592C >A polymorphism in the IL10 gene in the main and control groups.

\begin{tabular}{|c|c|c|c|c|c|c|c|c|c|c|}
\hline \multirow{3}{*}{$\begin{array}{l}\text { Alleles and } \\
\text { genotypes }\end{array}$} & \multicolumn{4}{|c|}{ Number of examined alleles and genotypes } & \multirow{3}{*}{$\mathrm{Xi2}$} & \multirow{3}{*}{$\mathrm{p}$} & \multirow{3}{*}{$\mathrm{RR}$} & \multirow{3}{*}{$+95 \% \mathrm{Cl}$} & \multirow{3}{*}{ OR } & \multirow{3}{*}{$+95 \% \mathrm{Cl}$} \\
\hline & \multicolumn{2}{|c|}{ CPRS } & \multicolumn{2}{|c|}{ Control } & & & & & & \\
\hline & $\mathrm{n}$ & $\%$ & $\mathrm{n}$ & $\%$ & & & & & & \\
\hline $\mathrm{C}$ & 50 & 80,65 & 141 & 96,58 & 14,715 & 0,706 & 0,835 & 1,788 & 0,148 & 0,393 \\
\hline$A$ & 12 & 19,35 & 5 & 3,42 & 14,715 & 0,294 & 1,198 & 5,121 & 6,768 & 17,980 \\
\hline $\mathrm{C} / \mathrm{C}$ & 24 & 77,42 & 51 & 69,86 & 0,006 & 0,313 & 1,010 & 3,343 & 1,035 & 2,505 \\
\hline$C / A$ & 8 & 25,81 & 19 & 26,03 & 0,077 & 0,325 & 0,904 & 3,305 & 0,874 & 2,267 \\
\hline $\mathrm{A} / \mathrm{A}$ & 2 & 6,45 & 3 & 4,11 & 0,164 & 0,314 & 1,431 & 12,630 & 1,458 & 9,061 \\
\hline
\end{tabular}

Table 3: Differences in the frequency of occurrence of alleles and genotypes of the rs1800895 592C>A polymorphism genotypes in the IL10 gene in group 2 of patients with CRS and the control group.

\begin{tabular}{|c|c|c|c|c|c|c|c|c|c|c|}
\hline \multirow{3}{*}{$\begin{array}{l}\text { Alleles and } \\
\text { genotypes }\end{array}$} & \multicolumn{4}{|c|}{ Number of examined alleles and genotypes } & \multirow{3}{*}{ Xi2 } & \multirow{3}{*}{$\mathrm{p}$} & \multirow{3}{*}{$\mathrm{RR}$} & \multirow{3}{*}{$+95 \% \mathrm{Cl}$} & \multirow{3}{*}{ OR } & \multirow{3}{*}{$+95 \% \mathrm{Cl}$} \\
\hline & \multicolumn{2}{|c|}{ CRS } & \multicolumn{2}{|c|}{ Control } & & & & & & \\
\hline & $\mathrm{n}$ & $\%$ & $\mathrm{n}$ & $\%$ & & & & & & \\
\hline C & 65 & 81,25 & 141 & 96,58 & 5,048 & 0,750 & 0,841 & 1,585 & 0,154 & 0,396 \\
\hline A & 15 & 18,75 & 5 & 3,42 & 15,048 & 0,250 & 1,189 & 5,322 & 6,508 & 16,767 \\
\hline $\mathrm{C} / \mathrm{C}$ & 27 & 67,5 & 51 & 69,86 & 0,067 & 0,371 & 0,966 & 2,719 & 0,896 & 2,052 \\
\hline $\mathrm{C} / \mathrm{A}$ & 11 & 27,5 & 19 & 26,03 & 0,029 & 0,349 & 1,057 & 3,133 & 1,078 & 2,569 \\
\hline $\mathrm{A} / \mathrm{A}$ & 2 & 5 & 3 & 4,11 & 0,048 & 0,352 & 1,217 & 10,582 & 1,228 & 7,647 \\
\hline
\end{tabular}

Table 4: Differences in the frequency of occurrence of alleles and genotypes of the rs1800895 592C >A polymorphism genotypes in the IL10 gene in groups 1 and 2 of patients.

\begin{tabular}{|c|c|c|c|c|c|c|c|c|c|c|}
\hline \multirow{3}{*}{ Alleles and genotypes } & \multicolumn{4}{|c|}{ Number of examined alleles and genotypes } & \multirow{3}{*}{$\mathrm{Xi2}$} & \multirow{3}{*}{$\mathbf{p}$} & \multirow{3}{*}{$\mathbf{R R}$} & \multirow{3}{*}{$+95 \% \mathrm{Cl}$} & \multirow{3}{*}{ OR } & \multirow{3}{*}{$+95 \% \mathrm{Cl}$} \\
\hline & \multicolumn{2}{|c|}{ CPRS } & \multicolumn{2}{|c|}{ CRS } & & & & & & \\
\hline & $\mathrm{n}$ & $\%$ & $\mathrm{n}$ & $\%$ & & & & & & \\
\hline C & 50 & 80,65 & 65 & 81,25 & 0,008 & 0,444 & 0,993 & 2,496 & 0,962 & 2,214 \\
\hline A & 12 & 19,35 & 15 & 18,75 & 0,008 & 0,556 & 1,008 & 2,096 & 1,040 & 2,418 \\
\hline $\mathrm{C} / \mathrm{C}$ & 24 & 77,42 & 27 & 67,5 & 0,082 & 0,435 & 1,046 & 3,070 & 1,156 & 3,121 \\
\hline $\mathrm{C} / \mathrm{A}$ & 8 & 25,81 & 11 & 27,5 & 0,152 & 0,473 & 0,856 & 2,756 & 0,811 & 2,326 \\
\hline $\mathrm{A} / \mathrm{A}$ & 2 & 6,45 & 2 & 5 & 0,028 & 0,457 & 1,176 & 8,557 & 1,188 & 8,942 \\
\hline
\end{tabular}

$\mathrm{OR}=0.15 ; 95 \% \mathrm{Cl}: 0.15-0.39)$, allele A prevailed statistically insignificantly in group $118.75 \%(\chi 2=15.04 ; P=0.25$; $\mathrm{RR}=1.18 ; \mathrm{OR}=6.50 ; 95 \% \mathrm{Cl}: 6.50-16.76)$. Homozygous genotype $A / A \quad(x 2=0.04 ; P=0.35 ; R R=1.21 ; O R=1.22$; 95\% Cl: 10.58-7.64) and heterozygous C/A genotype of the polymorphic locus rs1800895 $592 \mathrm{C}>\mathrm{A}$ in the IL10 gene in 2.0 times had a tendency to predominance among conditionally healthy surveyed persons, relative to patients with CPRS. These data indicate the presence of non-protective properties in relation to the development of CPRS $(\chi 2=0.02 ; P=0.34 ; R R=1.05 ; O R=1.07 ; 95 \% \mathrm{Cl}$ : 10.58-2.56).

The homozygous C/C genotype is characterized by the absence of differences in the frequencies of its detection among conditionally healthy individuals among patients of group 1 in which its detectability was at the same level $(\chi 2=0.06 ; \mathrm{P}=0.37 ; \mathrm{RR}=0.96 ; \mathrm{OR}=0.89 ; 95 \% \mathrm{Cl}: 2.71-2.05)$

Table 4 shows that both groups for all alleles of the study indicators, it can be concluded that with XPC and CPRS alleles and genotypes of the rs1800895 592 C > A polymorphism, no significant changes were found in the IL10 gene.

Summarizing the results obtained, we can conclude that there are no significant differences in the frequency of detection of allelic and genotypic variants of the rs 1800895 $592 \mathrm{C}>\mathrm{A}$ polymorphic locus in the IL10 gene in groups 1 and 2 of patients. There is no significant contribution of this locus to the formation and development of this or that form of XPC. However, in CPRS patients, in comparison with the control group, there is a significant tendency to a decrease in the frequency of the $A / A$ genotype. According to the odds ratio, the risk of CPRS formation in carriers of this genotype is increased by 2.4 times $(\chi 2=14.71 ; \mathrm{P}=0.70 ; \mathrm{RR}=0.83 ; \mathrm{OR}=0.14 ; 95 \% \mathrm{Cl}$ : 1.78-0.39).

\section{CONCLUSION}

The revealed reliably high frequency of this genotype in group 1 of patients with CPRS, compared with group 2 of CPRS, also confirms our assumption about the protective role of the genotypic variant of the $A / A$ polymorphism rs1800895 $592 \mathrm{C}>\mathrm{A}$ in the IL10 gene, in relation to the development of CPRS in patients $(6.45 \%$ versus $5.0 \%$, respectively, at $\chi 2=0.02 ; \mathrm{P}=0.45 ; \mathrm{RR}=1.17 ; \mathrm{OR}=1.18$; $95 \% \mathrm{Cl}: 8.557-8.942)$. This fact is probably due to the fact that in carriers of the A/A genotype of the IL10 gene, the anti-inflammatory activity of epithelial matrix metalloproteinases is significantly increased, compared with patients carrying other genotypic variants. 


\section{ACKNOWLEDGEMENTS}

\section{Funding Support: FAPESP project 2016/20176-4}

\section{CONFLICT OF INTEREST}

The authors declares no conflict of interest

\section{REFERENCES}

1. Shen C, Chen F, Wang H, Zhang X, Li G, Wen Z. Individualized treatment for allergic rhinitis based on key nasal clinical manifestations combined with histamine and leukotriene D4 levels 5 . Brazilian J Otorhinolaryngol. 2020;86:63-73.

2. Resende EP, Todo-Bom A, Loureiro C, Pinto AM, Oliveiros B, Mesquita $L$, et al. Asthma and rhinitis have different genetic profiles for IL13, IL17A and GSTP1 polymorphisms. Revista Portuguesa de Pneumologia (English Edition). 2017;23:10-6.

3. Valera FC, Endam LM, Ibrahim B, Brochiero E, Desrosiers MY. Is there a role for regenerative medicine in chronic rhinosinusitis with nasal polyps?,Brazilian J Otorhinolaryngol. 2017;83:1-2.

4. Gross GN, Berman G, Amar NJ, Caracta CF, Tantry SK. Efficacy and safety of olopatadine-mometasone combination nasal spray for the treatment of seasonal allergic rhinitis. Ann of Allergy, Asthma \& Immunol. 2019;122: 630-8.

5. Braun JJ, Riehm S. Anosmia and nasal obstruction. Eur Ann of Otorhinolaryngol, Head and Neck Dis. 2018;135:217-9.

6. Guttemberg MD, Mata FA, Nakanishi M, de Andrade KR, Pereira MG. Sleep quality assessment in chronic rhinosinusitis patients submitted to endoscopic sinus surgery: a meta-

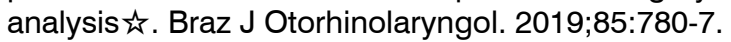

7. Miyake MM, Nocera A, Miyake MM. P-glycoprotein and chronic rhinosinusitis. World $\mathrm{J}$ Otorhinolaryngol-Head and Neck Surg. 2018;4: 169-74.

8. Daramola OO, Chandra RK. Chronic rhinosinusitis and endoscopic sinus surgery. World J Otorhinolaryngol-Head and Neck Surg. 2018;4:29-32.

9. Traina G, Valluzzi RL, Fierro V, Riccardi C, Artesani MC, De Vuono A, et al. Proceedings of the 2017 WAO Symposium on Hot Topics in Allergy: Pediatric \& Regulatory Aspects. InWorld Allergy Organization J. 2017;10: 1-16. BioMed Central.
10. Ankowski R, Gallet P, Nguyen DT, Rumeau C. Chronic respiratory rhinitis. European Ann of Otorhinolaryngol, Head and Neck Dis. 2018;135: 255-8.

11. Khalmuratova R, Shin HW, Kim DW, Park JW. Interleukin (IL)13 and IL- 17A contribute to neo-osteogenesis in chronic rhinosinusitis by inducing RUNX2. EBioMed. 2019;46:330-41.

12. Mueller SK. Exosomes and chronic rhinosinusitis. World J Otorhinolaryngol-Head and Neck Surg. 2018;4:175-8.

13. Weber SA, lyomasa RM, Corrêa CD, Florentino WN, Ferrari GF. Nasal polyposis in cystic fibrosis: Follow-up of children and adolescents for a 3-year period. Brazilian $\mathrm{J}$ Otorhinolaryngol. 2017;83:677-82.

14. Laidlaw TM. Pathogenesis of NSAID-induced reactions in aspirin-exacerbated respiratory disease. World J Otorhinolaryngolo-Head and Neck Surg. 2018;4:162-8.

15. Dinarte VR, Santos AR, Araújo LF, Reis MG, Tamashiro E, Valera FC, et al. Polymorphisms in chronic rhinosinusitis with nasal polyps-a systematic review. Braz J Otorhinolaryngol. 2017;83:705-11.

16. Bao J, Wang YH, Liu QH, Bao YX, Azouz N, Caldwell J, et al. WAO International Scientific Conference (WISC 2016) Abstracts. InWorld Allergy Organization J 2017;10:1-39.

17. Morii W, Sakai A, Ninomiya T, Kidoguchi M, Sumazaki R, Fujieda S, et al. Association of Japanese cedar pollinosis and sensitization with HLA-DPB1 in the Japanese adolescent. Allergol Int. 2018;67:61-6.

18. Dekant W, Scialli AR, Plotzke K, Klaunig JE. Biological relevance of effects following chronic administration of octamethylcyclotetrasiloxane (D4) in Fischer 344 rats. Toxicol Letters. 2017;279:42-53.

19. Noyama $Y$, Okano M, Fujiwara T, Kariya S, Higaki T, Haruna T, et al. IL-22/IL-22R1 signaling regulates the pathophysiology of chronic rhinosinusitis with nasal polyps via alteration of MUC1 expression. Allergol Int. 2017;66:42-51.

20. Wen YS, Lin CY, Yang KD, Hung CH, Chang YJ, Tsai YG. Nasal nitric oxide is a useful biomarker for acute unilateral maxillary sinusitis in pediatric allergic rhinitis: A prospective observational cohort study. World Allergy Organization J. 2019;12:100027. 